\title{
Small Clause Results Revisited ${ }^{*}$
}

\author{
Jaume Mateu \\ (Universitat Autònoma de Barcelona) \\ jaume.mateu@uab.es
}

To Ken Hale and Teun Hoekstra,
sine quibus non

\begin{abstract}
The main purpose of this paper is to show that argument structure constructions like complex telic path of motion constructions (John walked to the store) or complex resultative constructions (The dog barked the chickens awake) are not to be regarded as "theoretical entities" (Jackendoff (1997b); Goldberg (1995)). As an alternative to these semanticocentric accounts, I argue that their epiphenomenal status can be shown iff we take into account some important insights from three syntactically-oriented works: (i) Hoekstra's $(1988,1992)$ analysis of $\mathrm{S}<$ mall $>C<$ lause $>$ R<esults>, (ii) Hale \& Keyser's (1993f.) configurational theory of argument structure, and (iii) Mateu \& Rigau's (1999; i.p.) syntactic account of Talmy's (1991) typological distinction between 'satelliteframed languages' (e.g., English, German, Dutch, etc.) and 'verb-framed languages' (e.g., Catalan, Spanish, French, etc.). In particular, it is argued that the formation of the abovementioned constructions involves a conflation process of two different syntactic argument structures, this process being carried out via a 'generalized transformation'. Accordingly, the so-called 'lexical subordination process' (Levin \& Rapoport (1988)) is argued to involve a syntactic operation, rather than a semantic one. Due to our assuming that the parametric variation involved in the constructions under study cannot be explained in purely semantic terms (Mateu \& Rigau (1999)), Talmy's (1991) typological distinction is argued to be better stated in lexical syntactic terms.
\end{abstract}

\section{Constructions: Theoretical entities or epiphenomena?}

The main purpose of this paper is to show that argument structure constructions like those exemplified in (1) are not to be regarded as "theoretical entities". In particular, I will be arguing against Goldberg's (1995) and Jackendoff's (1997b) claims quoted in (2) and (3), respectively.
a. They danced the night away.
b. Morris moaned his way out of the hall.
c. He sneezed the tissue off the table.
d. The dog barked the chickens awake.
e. The truck rumbled into the yard.
f. The boy danced into the room.
("The time-away construction")
("The way-construction")
("The caused motion construction")
("The resultative construction")
("Sound verbs in path of motion constructions")
("Manner of motion verbs in path of motion constructions")

(2) "In the past two decades, the pretheoretical notion of construction has come under attack. Syntactic constructions have been claimed to be epiphenomenal, arising solely from the interaction of general principles (Chomsky $(1981,1992))$; the rejection of

\footnotetext{
* I would like to thank the audience at the Workshop on the Syntax of Predication for many comments and suggestions. Needless to say, all remaining errors are my own. Research for this paper has been supported by the Ministerio de Ciencia y Tecnologia (BFF2000-0403-C02-01), and the Generalitat de Catalunya (1999SGR00113).
} 
constructions in favor of such general principles is often assumed now to be the only way to capture generalizations across patterns (...).

(...) This monograph represents an effort to bring constructions back to their rightful place on center stage by arguing that they should be recognized as theoretical entities" <emphasis added: $\mathrm{JM}$ >

Goldberg (1995: 1-2).

(3) "The task for linguistic theory is not to struggle to eliminate the need for such constructions <like those in (1): JM>. Rather, it is to discover the range of such constructions permitted by UG such that the child can acquire them"

\section{Jackendoff (1997b: 558)}

Concerning Jackendoff's claim in (3), it is clear that generative syntacticians and Jackendoff are talking at cross-purposes, that being due to their different conception of what UG is supposed to deal with. Jackendoff's statement in (3) must be understood in the context of his architecture of the language faculty. For example, in (4) is depicted his analysis of the so-called way-construction. According to Jackendoff, three different structures are independently generated, being related in a non-derivational way. UG is argued to be flexible enough in order to allow non-canonical correspondences (stated in (4) via indices) like those involved in the way-construction. ${ }^{1}$

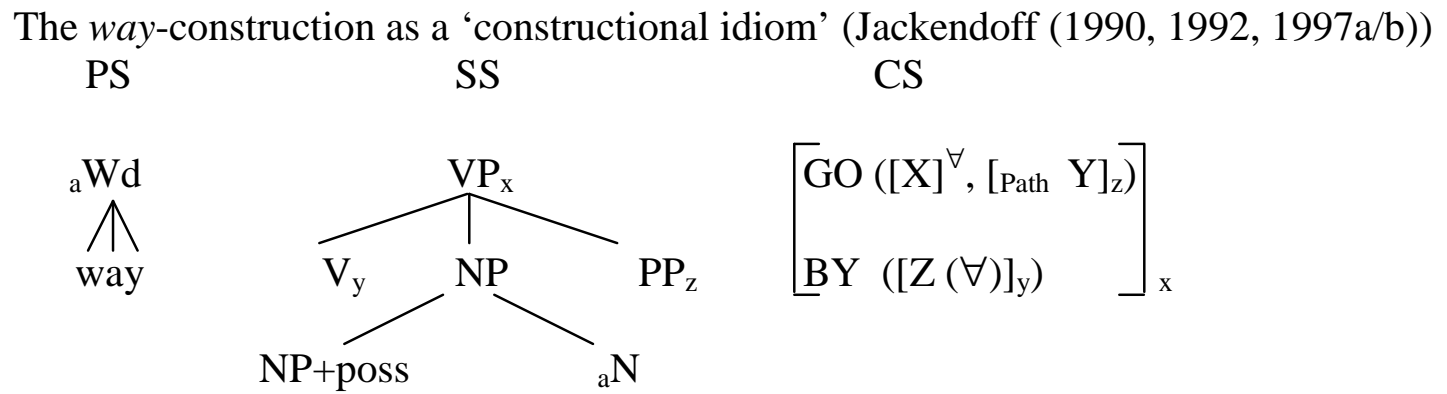

Jackendoff (1997a: 172)

In this paper I will assume a conception of the syntax-semantics interface which is different from that espoused in Jackendoff (1990f.). With Marantz (1992) and Mateu (2000a), I think that the unconstrained nature of Jackendoff's (1990f.) linking theory (cf. (5)) prevents him from recognizing the non-trivial role of syntax when dealing with constructions like those in (1).

"The work developed here leads to a position that might be termed 'autonomy of correspondence rules', the idea that the correspondence rules have their own properties and typology, to a considerable degree independent of the syntactic structures and

\footnotetext{
${ }^{1}$ Jackendoff points out that (4) licenses correspondences of syntactic structure (SS) and conceptual structure (CS) that do not follow canonical principles of argument structure mapping. As a result, the verb is not what licenses the argument structure of the rest of the VP; rather, the construction does. According to Jackendoff (1997a: 172), the CS in (4) can be read as saying that 'Subject goes along Path designated by PP, by V-ing' (sic).

See Marantz (1992) and Mateu (2000a) for a reply. The latter shows that Jackendoff's semantic analysis is not adequate, this being due to his neglecting (i) the causative nature of the way-construction and (ii) the semantic contribution of the way NP.
} 
conceptual structures that they relate (...). The richness of linking theory permits us to keep the syntax simple <emphasis added: JM>".

Jackendoff (1990: 286)

By taking a different perspective, I want to show the non-trivial role of (morpho)syntax when dealing with constructions like those in (1). By doing so, I will try to make it clear in which specific sense constructions like those in (1) can be taken as epiphenomena when analyzed from the present syntactic perspective. The specific sense by virtue of which I will be calling those constructions in (1) 'epiphenomena' will be shown to emerge when discussing a non-trivial question: Why is it the case that those constructions in (1) are typically found in some languages (e.g., in English), but not in others (e.g., in Romance)? Following syntactically-oriented work by Snyder (1995), Klipple (1997), and Mateu \& Rigau (1999, i.p.), I will show that the so-called 'resultativity/directionality parameter' is crucially involved in accounting for the syntax of those examples in (1). To put it crudely, constructions in (1) will be shown to be epiphenomena as far as their syntax is concerned because a more general morphosyntactic explanation seems to be involved, this accounting for why these constructions are possible in some languages but not in others.

To be sure, our recognizing that those constructions in (1) are epiphenomena should not prevent us from recognizing that there are non-trivial semantic peculiarities associated with them, those that make them 'idiomatic constructions'. However, with Marantz (1997), I think that their idiomaticity (i.e., what allows us to call those examples 'constructions') has nothing to do with syntax or the computational system, as we understand it (cf. (6)). Rather, their idiomatic character should be encoded in what Marantz (1997) recently calls the 'Encyclopedia', which is to be taken as the realm of special meanings. That is, it is at the interface with that non-generative component ('the Encyclopedia') where those special meanings are 'negotiated' (to use Marantz's terms) with those structural contexts provided by syntax.

"I deny the major assumption of Construction Grammar that such meanings may be structure-specific, rather than general for a language and generally universal (...) I would like to insist that neither phrasal idioms nor derived words have special structure/meaning correspondences (emphasis added: JM)".

Marantz (1997: 212)

Accordingly, it should be clear that, along with Marantz (1992, 1997), I disagree with Jackendoff's (1992) claim that a syntactic account of constructions like that in (4) would not be appropriate since there are lexical-semantic restrictions involved in their formation. Such a claim is a non-sequitur. Jackendoff's premise is simply false. Why syntax (e.g., the alleged syntactic rule in (7)) should take care about those semantic peculiarities?! (cf. Mateu (2000a)).

(7) "The movement rule has to be sensitive not only to the lower verb's being intransitivewhich seems reasonable- but also to its being an action verb that can be construed as an internally articulated process- which does not seem reasonable in a theory of autonomous syntax".

Jackendoff (1992: 170)

In this sense I disagree with Jackendoff's (1992: 170) claim that a syntactic account of the way-construction does not seem reasonable in a theory of autonomous syntax. According 
to him, for the syntactic account to be correct, the relevant syntactic rule or other autonomous syntactic principles should prevent sentences like those in (8) from being generated:

a. *Bill blushed his way out of the room.

b. $\quad *$ Bill had to crouch his way through the low opening. Jackendoff (1992: 170))

However, I will take pains to show that the relevant syntactic operation of conflation involved in (1), that concerning the computational system as we understand it, is sensitive not to a semantic reason but rather to a morphosyntactic reason. As noted above, the obvious and undeniable fact that there are semantic restrictions/peculiarities associated to the constructions in (1) does not affect their syntactic computation. Accordingly, I would like to propose that sentences like that in (8a) or that in (9) are freely generated by the computational system, ${ }^{2}$ their anomaly being detected in the non-generative component of the Encyclopedia, the idoneous place where the relevant semantic peculiarities/restrictions analyzed by Jackendoff and Goldberg are to be coded. ${ }^{3}$

\# The boy laughed into the room (cf. the truck rumbled into the yard)

It seems to me that Jackendoff's conception of an impoverished syntax makes him commit the same mistake as that exemplified by Spencer \& Zaretskaya's (1998) words quoted in (10).

“(...) resultatives are complex predicates formed at a semantic level of representation and not constructions formed in the syntax" (p. 4; emphasis added: JM) .

"(...) One indication that we need to form the complex predicate at a lexical level comes from the fact that many types of resultative are lexically restricted, in that only certain types of lexeme can serve as the syntactic secondary predicate" (p. 11; emphasis added: $\mathrm{JM}$ ).

Spencer \& Zaretskaya (1998: 4; 11)

With Hoekstra (1984, 1988, 1992), Hale \& Keyser (1993f) and Marantz (1997), I disagree with Spencer and Zaretskaya's (1998) fallacious claim that showing that a process has lexical-semantic restrictions is an inevitable sign that syntactic formation is not involved.

Notice then that what Goldberg's (1995), Jackendoff's (1990f.) and Spencer \& Zaretskaya's (1998) semantic approaches have in common is that all minimize the role of syntax when dealing with resultative-like constructions such as those in (1). Moreover, notice that they have nothing interesting to offer concerning the non-trivial question of why constructions like those in (1) are present in some languages (e.g., in Germanic languages), but absent from others (e.g., from Romance languages). Unfortunately, they are not alone in

\footnotetext{
${ }^{2}$ Was the case that blush is an unergative verb in English (see Levin \& Rappaport Hovav (1995: 160)), it would be better to replace * ('ungrammatical') by \# ('semantically deviant') in ( 8 a). By contrast, (8b) could be analyzed as ungrammatical, provided we show that the verb crouch is an unaccusative verb. See below for the syntactic constraint that only unergative verbs (unergative use of transitive verbs included) are allowed to enter into those constructions in (1).

${ }^{3}$ The computational system is not concerned with the lexical-semantic difference between [GO-laugh] and [GOrumble]: That is, the fact that the sound of 'rumbling' can be taken as partaking of an intrinsic relation with an inherently directed motion event, whereas that of 'laughing' cannot, is a "lexical" fact to be coded in the Encyclopedia of English. No matter how systematic that semantic relation turns out to be across languages (e.g., (9) is out in German as well), that semantic difference is fully opaque to the computational system.
} 
being unable to provide a principled explanation of the crosslinguistic variation issue: for example, what could it mean to say that Romance languages lack the relevant LCS operation (Levin \& Rapoport (1988); Legendre (1997); Spencer \& Zaretskaya (1998)), the relevant aspectual operation (Tenny (1994), the relevant event type-shifting operation (Pustejovsky (1991); van Hout (1996)), or whatever relevant semantic operation to be invented in the days to come? I will not review my criticism of these aspectual/event structure-based approaches here (see Mateu (2000b; 2001a)), but I will limit myself to pointing out that the solution of such a linguistic variation problem cannot be stated in purely aspectual or event structure terms. To be sure, I do not want to deny the relevance of the aspectual semantics in analyzing the data in (1) nor the descriptive insights found in the abovementioned works. Here I will concentrate on showing that morphosyntax has a non-trivial role in accounting for the parametrized variation involved in (1).

As an alternative to the semanticocentric accounts, I think that the syntactic approach to constructions like those in (1) has some important insights to offer concerning their epiphenomenal status, basically those provided by the three following syntactically-oriented works in (11):

(11) (i) Hoekstra's $(1988,1992)$ analysis of $\mathrm{S}<$ mall $>C<$ lause $>\mathrm{R}<$ esults $>$

(ii) Hale \& Keyser's (1993f.) syntactic theory of argument structure (adopted by Chomsky (1995))

(iii) Mateu \& Rigau's (1999;i.p.) syntactic account of Talmy's (1991) typological distinction between 'satellite-framed languages' (e.g., Germanic languages) and 'verb-framed languages' (e.g., Romance languages).

\section{Hoekstra's $(1988,1992) \mathrm{S}<$ mall $>$ C $<$ lause $>$ analysis}

Hoekstra (1992) analyzed resultative constructions from an interesting perspective that combined Stowell's (1981) SC theory with some insights on aspect taken from event semantics works (Carlson (1977); Kratzer (1988)). According to Hoesktra (1992: 161-162),

(12) "We can isolate the circumstances under which a resultative may be found: the predication must be stage-level <(e.g., cf. *This enclyclopedist knows individual level [sC all books superfluous])> and dynamic <(e.g., cf. *Medusa saw-dynamic [SC the hero into stone])>, but not inherently bounded (e.g., <e.g., cf. *The psychopath killed ${ }_{+ \text {bounded }}$ ISC $_{\text {the }}$ village into a ghost town]>)".

Hoesktra (1992: 161-162)

In those examples in (1), repeated below in (13), the verb expresses a stage level, dynamic, and not inherently bounded predicate. ${ }^{4}$

(13) a. They danced [sc the night away].

b. Morris moaned [sc his way out of the hall].

c. He sneezed [sc the tissue off the table].

d. The dog barked [sc the chickens awake].

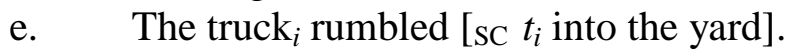

f. The boy $_{i}$ danced [sc $t_{i}$ into the room].

\footnotetext{
${ }^{4}$ Quite importantly, Hoekstra $(1984,1988$, 1992) provided extensive evidence in favor of positing a syntactically-based unaccusativization process of those unergative verbs in (13e-f).
} 
On the other hand, as emphasized by Hoekstra (1988: 138) in (14), the SC analysis defines the upper bounds of the distribution of resultative SCs, that is to say, the structural ones. Moreover, it should be clear that he was aware of the fact that "the distribution appears to be more restricted". That is, Hoekstra was aware of the fact that there are additional semantic peculiarities involved in resultatives. However, he considered them as falling outside of the theory of the I-Language. Notice then the compatibility of Hoekstra's claim with our claim of encoding those semantic peculiarities alluded to above in the so-called 'Encyclopedia component' (to put it in Marantz's terms).

(14) "The present analysis defines the upper bounds <emphasis added: JM> of the distibution of resultative SCs (...) In fact, the distribution appears to be more restricted, showing that language does not fully exploit its resources. What we have here is parallel to the distinction between actual and possible words, familiar from the domain of morphology (...) The gap between the possible and the actual is not to be bridged by a theory of the I-Language, but belongs to the domain of the E-language in the sense of Chomsky (1986) <emphasis added: JM>".

Hoekstra (1988: 138)

On the other hand, Hoekstra made another invaluable contribution to the linguistic theory by showing the flaws of some current lexicalist theories. As Hoekstra (1988: 138) noted, "the common distinction between lexical word making and non-lexical sentence making is questionable at best". For example, he showed that structurally, the c- and dexamples in (15) are identical, "consisting of the activity denoting verb, taking a SC complement which is interpreted as a resulting state" (p. 166): see (16).
a. dat Jan bier drinkt.
that John beer drinks
b. $\quad *$ dat Jan zich drinkt. that John himself drinks
c. dat Jan zich dronken drinkt. that John himself drunk drinks
d. dat Jan zich bedrinkt. that John himself BE-drinks

(Dutch)

Hoekstra (1992: 166)

\section{drinkt [sc zich $\{$ dronken/BE- $\}]$}

Hoekstra was succesful in showing that the alleged distinction between "syntactic formation" (cf. the "syntactic object' in (15c)) and "lexical formation" (cf. the "morphological object' in (15d)) seems to be questionable. Notice then the compatibility of Hoekstra's attacks of Lexicalism with Hale \& Keyser's (1993f.) or Marantz's (1997) syntactically-based approaches to derivational morphology.

Hoekstra's insights on SCRs notwithstanding, I would like to emphasize here that there is non-trivial problem that remains unaccounted for in his syntactic approach. In particular, notice that what Hoekstra's theory, as it stands, does not explain is the crosslinguistic variation involved: No explanation is provided concerning the so-called 'directionality/resultativity parameter' (see Snyder (1995); Mateu \& Rigau (1999), among others). For example, what prevents Romance speakers from forming SCRs like those in 
(13)? That is, why is it the case that activity verbs in Romance cannot typically take a SCR complement? To be sure, those questions can be said to be "innocuous" for constructionalists like Jackendoff but they should not be so for Hoekstra's syntactic approach.

According to Jackendoff, it is simply the case that Romance languages lack the relevant 'correspondence rule', in particular his Verb Subordination Archi-construction depicted in (17), which is said to account for all those cases in (1). Thus, for example, 'the time-away construction' in (1a) can be regarded as a particular instantiation of the 'Archiconstruction' in (17): see (18).

(17) Verb Subordination Archi-construction (Jackendoff (1997b))

a. [vp V....]

b. 'act (by) V-ing'
a. [vP V NP away]
b. 'waste [Time NP] by V-ing'

Jackendoff (1997b: exs. (101-102); 554-555)

Despite the descriptive merits of Jackendoff's constructional approach, here I would like to argue that Hoekstra's syntactic approach can be shown to be more explanatory than the non-syntactically based semantic approaches iff it is complemented by Mateu \& Rigau's (1999; in press) lexical syntactic account (Hale \& Keyser (1998)) of Talmy's (1991) typological distinction between satellite-framed languages (e.g., Germanic languages) and verb-framed languages (e.g, Romance languages).

Before analyzing the relevant parameter involved in Talmy's (1991) typological distinction, it will be useful to sketch out briefly the fundamentals of Hale \& Keyser's (1998, 1999a) configurational theory of argument structure, which my analysis of constructions like those in (1) will be argued to depend on. Quite crucially, an important modification/reduction of Hale \& Keyser's basic argument structure combinations will be shown to be motivated by my unified approach to complex telic path of motion constructions (e.g., The boy danced into the room) and adjectival resultative constructions (e.g., The dog barked the chickens awake) (cf. Mateu (2000b)).

\section{The syntax of argument structure (Hale \& Keyser (1998;1999a))}

According to Hale \& Keyser (1999a: 454):

(19) Argument structure is defined in reference to two possible relations between a head and its arguments, namely, the head-complement relation and the head-specifier relation.

A given head (i.e., $x$ in (20)) may enter into the following structural combinations in (20): "these are its argument structure properties, and its syntactic behavior is determined by these properties" (Hale \& Keyser (1999a: 455)).

(20) Head (x); complement ( $y$ of $x$ ), predicate $(x$ of $z$ )
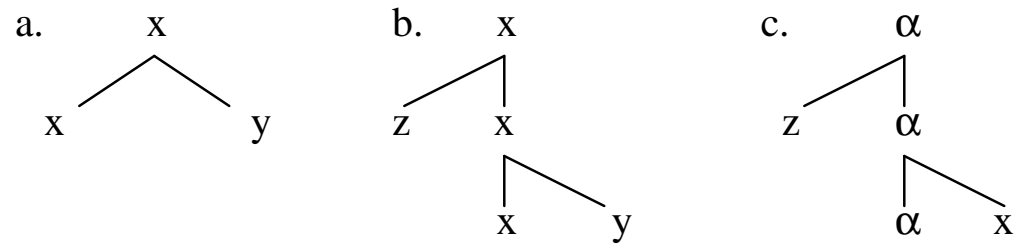

d. $\mathrm{x}$ 
According to Hale \& Keyser, the prototypical or unmarked morphosyntactic realizations in English of the lexical heads in (20) (i.e., the $x$ 's) are the following: $V$ in (20a), $P$ in (20b), $A$ in (20c), and $N$ in (20d).

The main empirical domain on which Hale \& Keyser's hypotheses have been tested includes denominal verbs (unergative verbs like laugh (cf. (21a)), transitive locative verbs like shelve (cf. (21b)), or locatum verbs like saddle (cf. (21c))), and deadjectival verbs (e.g., clear (cf. (21d)).

(21) a. John laughed.

b. John shelved the book.

c. John saddled the horse.

d. John cleared the screen.

Unergative verbs are argued to be transitive since they involve merging a noun with a verbal head , this resulting in (22a); both locative verbs (e.g., shelve) and locatum verbs (e.g., saddle) involve merging the structural combination in (20b) into that of (20a): see (22b). Finally, transitive deadjectival verbs also involve two structural combinations, i.e., that in (20c) is merged into that of (20a): see (22c).

(22)

a.<smiles>[Y]C([Y])N</smiles>

b.

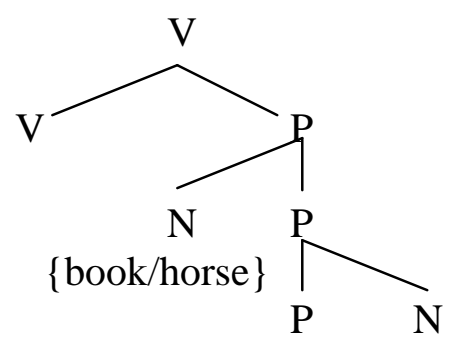

$\{$ shelf/saddle $\}$

c.

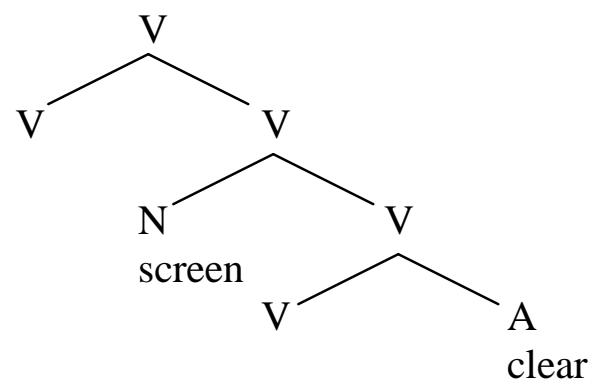

Locative and locatum verbs are said to be transitive (cf. (23a)) because their inner Pprojection cannot occur as an autonomous predicate. By contrast, deadjectival verbs can be intransitive ((cf. (23b)), since their inner V-projection can occur as an autonomous predicate. Crucially, notice that it can be associated with tense morphology.

(23) a. *The book shelved; *The horse saddled.

b. The screen cleared. 
Furthermore, as justified in Hale \& Keyser (1993f.), the external argument of transitive constructions (unergatives included) is argued to be truly external to the argument structure configuration. It will appear as the specifier of a functional projection in s(entential)syntax.

Both denominal and deadjectival verbs implicate a process of conflation, essentially an operation that copies a full phonological matrix into an empty one, this operation being carried out in a strictly local configuration: i.e., in a head-complement one. If Conflation can be argued to be concomitant of Merge (Hale \& Keyser (1999a)), the argument structures in (22) turn out to be quite abstract since they have been depicted as abstracted away from those conflation processes involved in the examples in (21). Applying the conflation operation to (22a) involves copying the full phonological matrix of the noun laugh into the empty one corresponding to the verb. Applying it to (22b) involves two steps: the full phonological matrix of the noun $\{$ shelf/saddle $\}$ is first copied into the empty one corresponding to the preposition; since the phonological matrix corresponding to the verb is also empty, the conflation applies again from the saturated phonological matrix of the preposition to the unsaturated matrix of the verb. Finally, applying the conflation process to (22c) involves two steps as well: the full phonological matrix of the adjective clear is first copied into the empty one corresponding to the internal verb; since the phonological matrix corresponding to the external verb is also empty, the conflation applies again from the saturated phonological matrix of the inner verb to the unsaturated matrix of the external verb.

To conclude my review of Hale \& Keyser's (1999a) theory of argument structure, it is important to keep in mind that both aspects of the conflation processes, the syntactic and the lexical, are regarded by Hale \& Keyser in no way as incompatible. See their relevant quotes in (24).

(24) "Our conservative position holds that the lexical entry of an item consists in the syntactic structure that expresses the full system of lexical grammatical relations inherent in the item".

Hale \& Keyser (1993: 98)

"Argument structure is the system of structural relations holding between heads (nuclei) and the arguments linked to them, as part of their entries in the lexicon <emphasis added: JM>. Although a lexical entry is much more than this, of course, argument structure in the sense intended here is precisely this and nothing more".

Hale \& Keyser (1999a: 453)

"Conflation is a lexical matter in the sense that denominal verbs, and deadjectival verbs as well must be listed in the lexicon. Although their formation has a syntactic character, as we claim, they constitute part of the lexical inventory of the language. The two characteristics, the syntactic and the lexical, are in no way incompatible <emphasis added: JM>".

Hale \& Keyser (1999a: 453)

Notice that adopting the conservative position alluded to in their first quote in (24) leads Hale \& Keyser to posit the existence of phrasal projection in the lexicon. In order to avoid such a potential contradiction, Uriagereka (1998) argues that those structures given in (22) are not lexical representations, but syntactic structures corresponding to lexical representations, after they are selected from the numeration. For example, according to 
Uriagereka, (25) could be taken as the actual lexical representation of the denominal verb saddle that determines the syntactic structure in $(22 \mathrm{~b}){ }^{5}$

$$
\begin{aligned}
& \left(\begin{array}{l}
-\mathrm{N} \\
+\mathrm{V} \\
\mathrm{F}-\mathrm{P}
\end{array}\right)\left(\begin{array}{l}
-\mathrm{N} \\
-\mathrm{V} \\
\mathrm{V}-\mathrm{F} \\
\mathrm{F}-\mathrm{N}
\end{array}\right]\left[\begin{array}{l}
+\mathrm{N} \\
-\mathrm{V} \\
\mathrm{P}-\mathrm{F}
\end{array}\right) \\
& {[\text { e.g., } \mathrm{V}+\mathrm{P}+\text { saddle }] \quad \text { Uriagereka }(1998: 438)}
\end{aligned}
$$

Since my present concern (i.e., to provide a syntactic account of resultative-like constructions such as those in (1)-(13)) does not crucially hinge on Uriagereka's refinements in order to properly derive syntactic structures like that in (22b), I will omit such a discussion here and I will continue to use syntactic structures à la Hale \& Keyser, with the proviso that I do not necessarily assume their conservative position, i.e., that these syntactic argument structures are encoded as such into the Lexicon.

\section{On the non-primitive status of argument structure properties of 'Adjectives'}

In this section, I put forward the hypothesis that the lexical head $x$ in (20c) is not to be seen as an atomic element, as in Hale \& Keyser's approach, but as a composite unit: in particular, the lexical head $x$ in (20c), whose unmarked morphosyntactic realization in English is the category Adjective $(A)$, can be argued to be decomposed into two more primitive lexicalsyntactic elements: ${ }^{6}$ I claim that $A$ involves the conflation of a non-relational element like that expressed by the lexical head $y$ in (20b) into a relational element like that expressed by the lexical head $x$ in (20b). That is to say, the structural combination in (20b) allows us to account for the argument structure properties of $A$ s as well. Accordingly, the 'small clause'-like argument structure involved in two sentences like those in $(26 a, b)$ turns out to be the same, that in (26c). Quite crucially, I claim that the conflation of $y$ into $x$ involved in $A$ accounts for both its relational or predicative character, which $A$ shares with $P$, and its nominal properties, which $A$ shares with $N{ }^{7}$

$$
\begin{aligned}
& \text { a. is [the cat [in the room]] } \\
& \text { b. is [the cat [happy]] } \\
& \text { c. is }\left[{ }_{x} z\left[\begin{array}{ll}
{ }_{x} x & y
\end{array}\right]\right]
\end{aligned}
$$

Furthermore, the decomposition of adjectives into a relational element plus a nonrelational element appears to be quite natural from a conceptual perspective as well. For

\footnotetext{
${ }^{5}$ According to Uriagereka (1998: 434), "the features in question <those in (i): JM> are purely combinatorial markings, uninterpretable formal features of words like saddle and shelve that are idiosyncratic to each of these verbs"

$\begin{array}{llll}\mathrm{F}-\mathrm{P} & = & \text { feature-P } & \text { ("a-Prep-incorporates-into-me") } \\ \mathrm{V}-\mathrm{F} & = & \text { v-feature } & \text { ("I-incorporate-into-v") } \\ \mathrm{F}-\mathrm{N} & = & \text { feature-N } & \text { ("a-Noun-incorporates-into-me") } \\ \mathrm{P}-\mathrm{F} & = & \text { P-feature } & \text { ("I-incorporate-into-P") }\end{array}$

6 At first glance, this hypothesis should not be surprising at all: the fact that the A category is missing in some languages is coherent with its secondary status.

${ }^{7}$ For example, the fact that languages like Latin mark $A$ s with morphological case can be taken as empirical evidence in favor of their nominal nature.
} 
example, from a Jackendovian perspective, the Conceptual Structure assigned to (27a) can be argued to contain a relational element introducing an abstract Place (AT). In fact, this extension is clearly expected under the so-called 'Thematic Relations Hypothesis' (Gruber (1965), Jackendoff $(1983,1990))$, according to which the same conceptual functions we use when dealing with physical space (e.g., $B E, G O, A T$, $T O$, etc. ) can also be applied to our conception of abstract space. ${ }^{8}$

(27) a. The door is open.

b. [State BE [Thing DOOR], [Place AT [Property OPEN]]]

On the other hand, more relevant for the purposes of the present paper is the fact that such a parallelism between physical and abstract spatial domains receives in turn further empirical support when considering the crosslinguistic morphosyntactic properties of resultative predicates: e.g., not only do Romance languages lack adjectival resultative constructions like the one in (28a), but prepositional ones like the one in (28b) are missing in these languages as well: ${ }^{9}$

a. Joe kicked the door open.
$\begin{array}{ll}\text { a'. } & \\ \text { *El Joe colpejà } & \text { la porta oberta. } \\ \text { b. Joe Joe kick-past-3rd.sing the door open } & \text { (Catalan) } \\ \text { b'. } & \text { *El Joe kicked the dog into the bathroom. } \\ & \text { The Joe kick-past-3rd.sing the dog inside the bathroom }\end{array}$

Quite interestingly, the "reduction" of the syntactic configuration in (20c) to the one in (20b) can be argued to be empirically motivated: the lexical-syntactic element corresponding to the 'terminal coincidence relation' (i.e. the telic Path) involved in both prepositional and adjectival resultatives can be argued to be the same, this being explicit in directional PPs like that in (28b), but covert in resultative APs like that in (28a). ${ }^{10}$ If we are willing to maintain that the relevant explanation accounting for the contrasts in (28) is basically morphosyntactic rather than purely semantic, it will be seen inevitable to decompose resultative APs in two different lexical syntactic elements: the relevant parameter must have access to the relational element incorporated in $A$ s, i.e., that corresponding to the telic directional relation. That is to say, to the extent that both prepositional and adjectival resultatives are treated in a uniform way as far as the lexical parameter is concerned, the decomposition of adjectival resultative predicates into two lexical syntactic elements seems to be justified.

Notice moreover that my modification or reduction of Hale \& Keyser's (1998/9) argument structure types becomes incompatible with their structural distinction between those denominal verbs involving Merge of (20b) into (20a), and those deadjectival verbs involving Merge of (20c) into (20a). According to Hale \& Keyser, it is precisely such a structural distinction that explains why the former are always transitive, while the latter can have an intransitive variant (the $\alpha$ verbal head in (20c) being then inflected with Tense).

\footnotetext{
${ }^{8}$ See Jackendoff (1990: 250) for a localistic analysis of the LCS corresponding to the \{causative/inchoative verb open.

${ }^{9}\left(28 a^{\prime}\right)$ and $\left(28 b^{\prime}\right)$ are grammatical on the following irrelevant readings: (28a') is grammatical if A is interpreted not as resultative but as attributive: i.e., 'the open door'; $(28 b$ ') is grammatical if the the PP has a locative, nondirectional reading: i.e., 'the kicking took place inside the bathroom'.

${ }^{10}$ See Jackendoff (1990) or Goldberg (1995) for their insight that AP resultative constructions involve an abstract Path.
} 
However, as Kiparsky (1997) and Mateu (2001b) have shown, Hale \& Keyser's generalization is not well-grounded (cf. (29)). According to Kiparsky, denominal verbs can participate in the causative/inchoative alternation if they denote events that can proceed without an explicit animate agent.

(29) "Denominal verbs do participate in the causative/inchoative alternation if they denote events which can proceed on their own (caramelize, shortcuit, carbonize, gasify, weather). This is also true for location verbs, such as those denoting mechanical processes which are understood as capable of proceeding on their own (reel, spool, stack, pile (up)), and the positioning of self-propelled vehicles (dock, berth, land) or of persons (bed, billet, lodge)".

Kiparsky (1997: 497)

On the other hand, Kiparsky points out that there are deadjectival verbs that can not participate in the causative/inchoative alternation: e.g., cf. legalize, visualize, etc.

Similarly, Levin and Rappaport Hovav's (1995: 104-105) examples in (30-31) also show that the licensing of the verb in the causative/inchoative alternation is more dependent on semantic conditions rather than on morphosyntactic ones. According to Levin \& Rappaport Hovav (1995: 105), "detransitivization is possible precisely where an externally caused eventuality can come about without the intervention of an agent.".

(30) a. The dressmarker lengthened the skirt.

b. *The skirt lenghtened.

c. The mad scientist lengthened the days.

d. The days lenghtened.

(31) a. The waiter cleared the table.

b. *The table cleared.

c. The wind cleared the sky.

d. The sky cleared.

Levin \& Rappaport Hovav (1995: 105)

That is to say, the relevant conclusion for my present purposes is the following one: the causative/inchoative alternation cannot be taken as a valid structural criterion when working out the relevant syntactic argument structures. In particular, the fact that denominal locative verbs like shelve or denominal locatum verbs like saddle do not enter into the causative/inchoative alternation is not due to a purely structural source, as Hale \& Keyser propose, but to the fact that they involve an animate agent.

This said, one important caveat is in order: my recognizing that the facts partly go with the semantics with respect to the causative/inchoative alternation should not be seen as incompatible with my adopting a syntactic approach to argument structure. Rather the relevant conclusion should be the following: those who are willing to adopt a pure syntactic approach to argument structure should avoid elaborating on complex hypotheses to explain facts that fall out of their program.

\section{The semantics of argument structure (Mateu \& Amadas (2001))}

The reduction of (20c) to (20b) is not only empirically supported, as we have pointed out in section 4, but is welcome from a theoretical perspective as well. My goal in this section is to 
show that this reduction strengthens the theoretically desirable claim that there is a strong homomorphism between the syntax and semantics of argument structure. ${ }^{11}$ The present proposal partakes of both Hale \& Keyser's (1993) paper, where certain meanings were associated with certain structures, and their more recent (1999a) paper, where a refinement of the basic argument structure types is presented. Quite importantly, Mateu \& Amadas (2001) argue that the reduction argued for in section 4 allows us to synthesize these two compatible proposals in quite an elegant and simple way. Given this reduction, the basic, irreducible argument structure types turn out to be those in (32).

a.

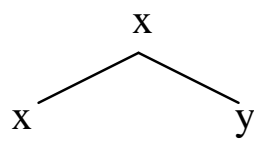

b.

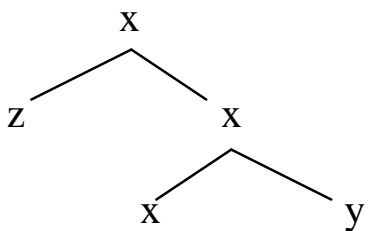

c. $\quad \mathrm{X}$

We claim that the reduction of (20) to (32) allows homomorphism to show up in the terms expressed in (33): given (33), the relational syntax of argument structure can be argued to be directly associated to its corresponding relational semantics in quite a uniform way:

(33) a. The lexical head $x$ in the syntactic configuration of (32a) is to be associated to an eventive relation.

b. The lexical head $x$ in the syntactic configuration of (32b) is to be associated to a non-eventive relation.

c. $\quad$ The lexical head $x$ in $(32 \mathrm{c})$ is to be associated to a non-relational element.

In turn, the eventive relation which is uniformly associated with the $x$ in (32a) can be instantiated as two different semantic relations: ${ }^{12}$ If there is an external argument in the specifier position of the relevant $F$ (unctional) projection (cf. Hale \& Keyser (1993f.)), the eventive relation will be instantiated as a source relation, the external argument being interpreted as 'Originator' (cf. Borer (1994) and Mateu (1999)). If there is no external argument, the eventive relation will be instantiated as a transitional relation (cf. Mateu (1999)), which in turn always selects a non-eventive relation (cf. (32b)), whose specifier and complement are interpreted as 'Figure' and 'Ground', respectively (this terminology being adapted and borrowed from Talmy (1985)).

The source relation is involved in transitive structures (cf. $x_{1}$ in (34)) and unergative structures (cf. $x_{1}$ in (35)), while the transitional relation is that involved in unaccusative structures (cf. $x_{1}$ in (36)). Notice that the only structural difference between transitive structures and unergative structures is based on the type of complement selected by the source relation: While a non-eventive relation is selected in (34) as complement, it is a non-relational element that is selected in (35). As a result, the transitive structure in (34) can be argued to partake of both an unergative structure (the eventive relation $x_{1}$ is interpreted as a source relation to be associated with an external argument $z_{1}$ via $F$ ) and an unaccusative structure ((34) includes a non-eventive relation $x_{2}$ ).

\footnotetext{
${ }^{11}$ See Bouchard (1995), Baker (1997) or Mateu (1999) for discussion on the homomorphic nature between the syntactic and semantic structures.

${ }^{12}$ In this sense our proposal is similar to that developed by Harley (1995). The main difference is that we, along with Hale \& Keyser (1993f.), do not analyze the syntactic head associated to the eventive relation as a functional one.
} 

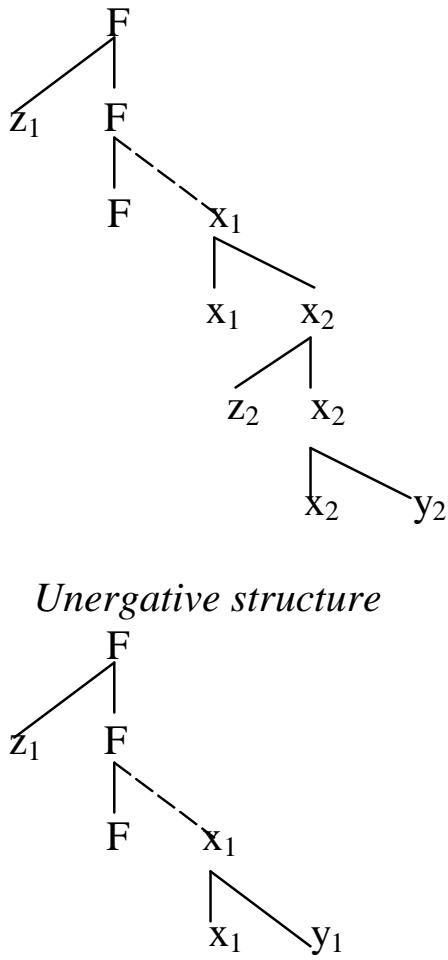

\section{Unaccusative structure}

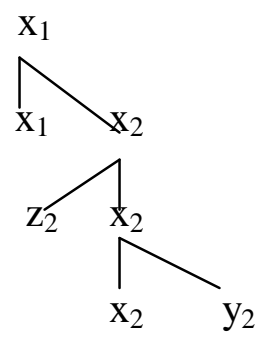

It is important to draw a crucial distinction between the constructional/configurational semantics that can be read off the mere syntactic structure and the lexical semantics that is expressed via semantic features associated to the particular lexical heads (Chomsky's (2001) semantic properties $\operatorname{SEM}(\mathrm{H})$ of the head). That is to say, the syntactic constructions in (34), (35), and (36) are to be associated to their corresponding structural meanings, independently of the particular lexical items that instantiate them (see Hale \& Keyser (1993) for a particular implementation of such a view). Structural semantic properties like eventive (\{source/transitional $\}$ ), non-eventive, and non-relational can then be argued to be directly read off the mere syntactic configurations. For example, the $x_{1}$ relation is to be read as a source relation in (34) and (35), but as a transitional relation in (36). The $x_{2}$ relation is to be read as a non-eventive relation in both (34) and (36).

There must be a compatibility between the structural semantic properties, those that can be read off the mere syntactic structure, and those semantic features of the lexical head. Let us assume that the latter semantic features are assigned to the lexical relational heads in a binary way like that exemplified in (37): ${ }^{13}$

\footnotetext{
${ }^{13}$ See Hale (1985) for the distinction between TCR and CCR.
} 
CAUSE/DO:

HAVE:

BECOME/GO:

$\mathrm{BE}$ :

Terminal Coincidence Relation (TCR):

Central Coincidence Relation (CCR): dynamic value of the source relation static value of the source relation dynamic value of the transitional relation static value of the transitional relation dynamic value of the non-eventive/spatial relation static value of the non-eventive/spatial relation

Notice that those binary values in (37) are not relevant to the syntactic projection of arguments. ${ }^{14}$ Consider the minimal pairs (38a-b) and (38c-d), and their corresponding argument structures in (39).

(38) a. John sent Peter to prison.

b. John kept Peter in prison.

c. Peter went to prison.

d. Peter was in prison.
a. [F John $\left[\mathrm{x}_{1}\right.$ CAUSE $\left[\mathrm{x}_{2}\right.$ Peter
b. $\quad\left[\mathrm{F}\right.$ John $\left[\mathrm{x}_{1}\right.$ HAVE $\left[\mathrm{x}_{2}\right.$ Peter
[x2 TO prison]]]]
c. $\quad\left[\mathrm{x}_{1} \mathrm{GO} \quad\left[\mathrm{x}_{2}\right.\right.$ Peter
[X2 IN prison]]]]
d.
$[\mathrm{x} 1 \mathrm{BE}$
[x2 $\mathrm{TO}$ prison]]]
[x2 IN prison]]]

Despite the different semantic values associated to the source relation (the dynamic one in (39a), and the static one in (39b)), and despite the different ones associated to the noneventive/spatial relation (TCR in (39a), and CCR in (39b)), it is nevertheless clear that both (39a) and (39b) are indistinguishable as far as their syntactic projection of arguments is concerned. This is due to the fact that both (39a) and (39b) project the very same argument structure, that in (34). Accordingly, in both (39a) and (39b), John is interpreted as 'Originator', Peter as 'Figure', and prison as 'Ground'.

Similarly, the same reasoning should be valid with respect to the minimal pair (39c)(39d): Despite the different semantic values associated to the transitional relation (the dynamic one in (39c), and the static one in (39d)), and despite the different ones associated to the non-eventive relation (TCR in (39c), and CCR in (39d)), it is nevertheless clear that both (39c) and (39d) are indistinguishable as far as their syntactic projection of arguments is concerned. This is due to the fact that both project the very same argument structure, the unaccusative structure in (36): Accordingly, in both cases Peter is interpreted as 'Figure', and prison as 'Ground'.

As it stands, notice that our claim that the semantic values in (39) are not directly relevant to the syntactic projection of argument structure, allows syntax to generate structures like that in (40b).
a. Peter stayed with him.
b. \# John stayed Peter with him.

\footnotetext{
${ }^{14}$ One important caveat is in order here: To be sure, our specific claim is not to be regarded as incompatible with the more general claim that those semantic values in (37) can be said to be relevant to grammatical processes. For example, see Tenny (1994: 190-192), where it is explicitly argued that the information associated to the CAUSE function or the GO function is essentially aspectual, ergo grammatically relevant.
} 


\section{c. [BE $\left[\mathrm{x}_{2}\right.$ Peter [x2 WITH him] ]] \\ d. \# [F John [x1 BE [x2 Peter [x2 WITH him $]]]]$}

Following Chomsky (2001: 9), we assume that theta-theoretic failures at the interface yield 'deviant structures' (cf. (41)). Given our set of present assumptions, (40b) is to be ruled out because of the failure induced by the incompatibility between the presence of an external argument and the semantic feature lexically associated to the eventive head of stay (i.e., BE). That is to say, the failure in (40b) is not to be regarded as syntactic in nature because nothing prevents (40b) from being attributed the configurational interpretation corresponding to the transitive structure in (34). That is, its mere syntactic configuration is interpretable: crucially, John in (40b) is structurally allowed to be interpreted as Originator. However, it is the case that 'verbs of existence', 'verbs of appearance', etc. do not appear to have an external causer, ${ }^{15}$ hence the deviance of (40b).

(41) "Uncontroversially, theta-theoretic properties depend in part on configuration and the semantic properties $\operatorname{SEM}(\mathrm{H})$ of the head (label). In the best case, they depend on nothing else (the Hale-Keyser version of theta theory). Assuming so, there are no sselectional features or theta-grids distinct from SEM $(\mathrm{H})$, which is typically a rich and complex structure, and theta-theoretic failures at the interface do not cause the derivation to crash; such structures yield 'deviant' interpreations of a great many kinds."

\section{Chomsky (2001: 9)}

Finally, I will conclude my sketchy review of Mateu \& Amadas (2001) with one important tenet of their theory of argument structure: There is no configurationally based lexical decomposition beyond 1-syntax. Accordingly, the lexical decomposition of verbal predicates (cf. (42) for a sample) stops at this coarse-grained level, the root being always associated to a non-relational element (cf. (43)). ${ }^{16}$ As a result, we want to embrace the nontrivial hypothesis that the only open-ended class of roots corresponds to non-relational elements, e.g., those occupying the specifier and complement positions in (43).
a. John corraled the horse.
b. John killed the horse.
c. John loved the horse.
d. John pushed the horse.
e. John laughed.
f. The horse died.
a. ${ }_{\mathrm{F}}$ John $\left[\mathrm{x}_{1}\right.$ CAUSE $\left[\mathrm{x}_{2}\right.$ the horse $\left[\mathrm{x}_{2}\right.$
TCR CORRAL]]]]
b. $\quad[\mathrm{F}$ John $[\mathrm{x} 1 \mathrm{CAUSE}[\mathrm{x} 2$ the horse $[\mathrm{x} 2$ TCR KILL]]]]

\footnotetext{
${ }^{15}$ See Levin \& Rappaport Hovav (1995). The fact that this class of verbs is consistently associated with an unaccusative syntax in English can be argued to be related to the claim that these verbs are lexically associated with the $\{\mathrm{GO} / \mathrm{BE}\}$ value. Accordingly, the lexical item stay is prevented from entering into a transitive argument

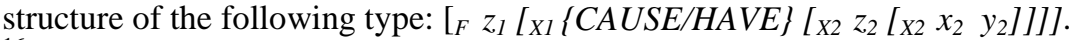

${ }^{16}$ The conceptual stuff depicted by caps must not be interpreted "as it stands". For example, we do not actually claim that the non-relational element CORRAL in (43a) is to be interpreted as the noun corral. Rather what is required is that CORRAL be interpreted as the non-relational element (i.e., the abstract Ground) included in the locative verb to corral (see Mateu (2001b)). The same holds for those morphologically less transparent cases: e.g., in $(43 \mathrm{~b}, \mathrm{f})$ what is meant by $\{K I L L / D I E\}$ is the non-relational element (i.e., the abstract Ground) included in the change of state verb $\{k i l l / d i e\}$.
} 


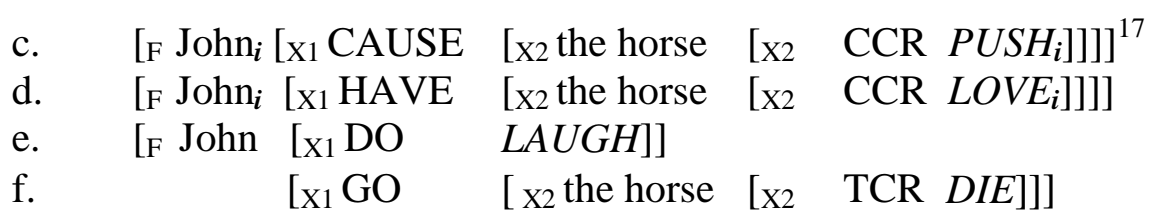

In other words, as far as the syntactically-based lexical decomposition is concerned, we claim that the non-relational element corresponding to the root in (43) (the root is depicted in italics) is a Fodorian-like monad. However, unlike Fodor, we think that a minimal lexical decomposition is necessary in order to provide an appropriate answer to theoretically interesting questions like those emphasized in (44). Without such a minimal lexical-syntactic decomposition, it is not clear to us which interesting answer could be provided to those nontrivial questions. To the best of our knowledge, no principled account has been given by Fodor concerning those two questions pointed out by Hale \& Keyser (1993) and addressed by Mateu (1999) or Mateu \& Amadas (2001).

(44) "It seems to us that one theoretically interesting insight to be found in Hale \& Keyser (1993) (in our view, one that strongly militates against a complex syntax-semantics interface like that envisioned by Jackendoff $(1990,1997))$ is their realizing that the following questions are intrinsically related: 'Why are there so few lexical categories?' I 'Why are there so few thematic roles?'. Notice that for Jackendoff it does not make sense to inquire into the relation of both questions. No doubt, we consider that important insight pointed out by Hale \& Keyser (1993) and developed by Mateu (1999) as providing us with a very strong theoretical argument in favor of the perfectly designed syntax-semantics interface envisioned by Chomsky (1995f.)".

Mateu \& Amadas (2001)

\section{The l-syntax of Small Clause Results}

After having presented the basics of our argument structure theory, let us return to the constructions under study in the present paper, those in (1). Since Hale \& Keyser appear to assume that phrase structure is exclusively projected from lexical heads, Jackendoff's point in (45) could be argued to be problematic for one willing to adopt their syntactic approach when dealing with resultative-like constructions such as those in (1).

(45) "Many contemporary theories of syntax proceed under the premise that phrase structure is projected exclusively from lexical heads. If the analysis proposed here is correct, these constructions <i.e., examples like those in (1): JM> constitute an interesting challenge to this premise, for in such constructions, the argument structure of the VP is licensed not by the verb, as in the usual situation, but by the construction itself".

Jackendoff (1997b: 534)

However, Jackendoff's (implicit) reasoning in (46) to be drawn from (45) is a non sequitur:

premise: phrase structure is projected exclusively from lexical heads

\footnotetext{
${ }^{17}$ See Hale \& Keyser (1999b) for the lexical syntactic analysis of atelic activity verbs like to push and atelic stative verbs like to love: According to them, the 'impact noun' push and the 'psych nominal' love must be linked to their source, the external argument, i.e., the s(entential)-syntactic subject. These nominal roots are supplied with a bracketed subscript representing a variable which must be bound obviatively. See Hale \& Keyser (1999b) for more details.
} 
then $(?)$

the argument structure of the VP is necessarily licensed by the surface verb.

That is to say, I would like to argue that the premise in (46) does not necessarily entail what is intended to entail in (46). Given this, Jackendoff's criticism of the premise in (46) does not hold. In fact, I will immediately show that assuming such a premise can be taken as fully compatible with providing an adequate syntactic account of the complex argument structure involved in examples like those in (1). In particular, as pointed out by Mateu \& Rigau (1999), the formation of resultative-like constructions like that in (1a) involves two different syntactic argument structures, the main one being transitive (e.g., that in (47a)), and the subordinate one being unergative (e.g., that in (47b)). The transitive structure in (47a) is associated to an 'accomplishment' (e.g., 'to cause y to go away'), ${ }^{18}$ while the unergative structure in (47b) is associated to an 'activity', (e.g., 'to do z').

a.

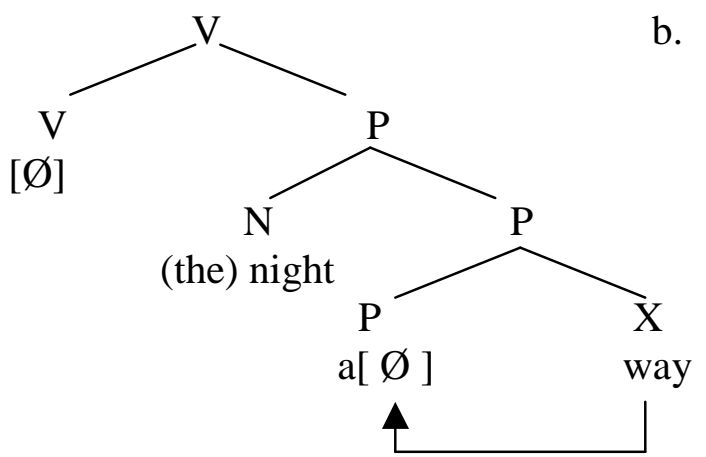

b.

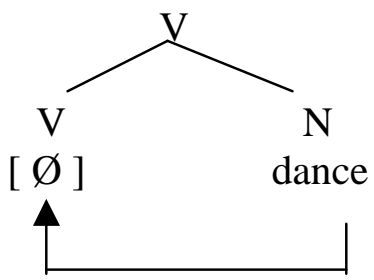

As I will show in the following section, it is precisely the non-conflating nature of the P element in (47a) what allows the complex verbal head in (47b) to be conflated/merged into the phonologically null transitive verb in (47a). Quite interestingly, Chomsky (1995) provides us with the adequate device for such a conflation process to be carried out: a 'generalized transformation'; see (48) for the resulting adjunction process.

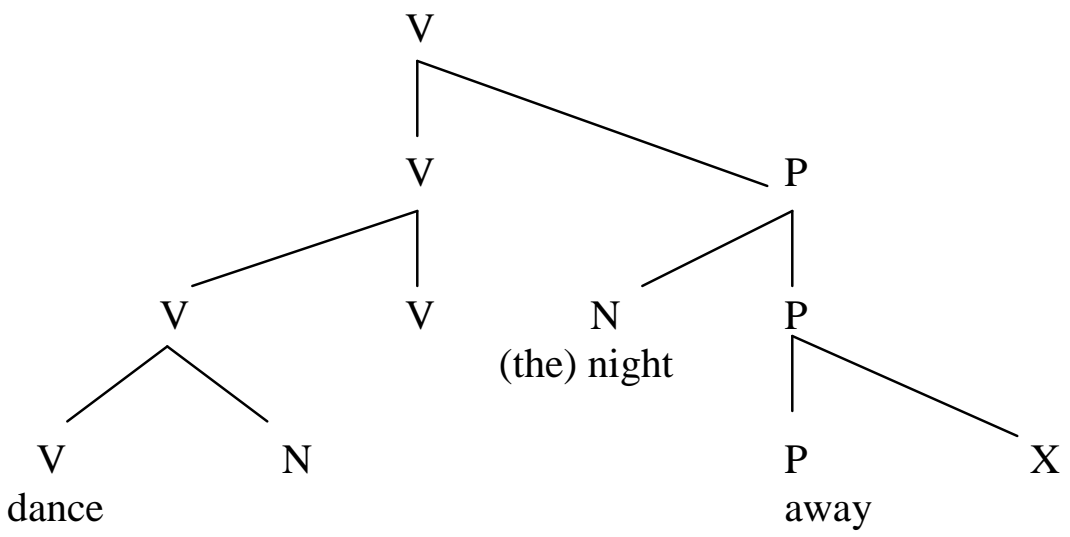

Accordingly, the semantic intepretation involved in the subordination process depicted in (49) can be argued to be associated to the complex syntactic argument structure in (48):

\footnotetext{
${ }^{18}$ Notice that Hoekstra's Small Clause constituent is to be translated into Hale \& Keyser's (1998) P projection, headed by a birelational telic 'Path' element (in their terms, a 'terminal coincidence relation'): it relates a 'Figure' (e.g., night) to an abstract 'Ground' (e.g., (a)way).

Moreover, notice that the external argument is not present in the syntactic argument structure, but is to be introduced by the relevant Functional projection (cf. Hale \& Keyser (1993f.) or Kratzer (1996)).
} 
(49) [(they) [[DO-dance]-CAUSE] [the night away]] (i.e., 'they caused the night to go away by dancing'). ${ }^{19}$

Unlike Levin \& Rapoport's (1988) or Jackendoff's (1990) semantic analyses, the present analysis of the so-called 'lexical subordination' as involving a syntactic operation should be regarded in full tune with Hale \& Keyser's (1993) particular interpretation of the Chomskian tradition of interpretivist semantics, which is summarized in their quote in (50):

(50) “(...) these semantic roles, like the elementary semantic interpretations in general, are derivative of the lexical syntactic relations <emphasis added: JM>".

Hale \& Keyser (1993: 72)

In the next section I will show that the empirical justification of my lexical syntactic analysis of resultative-like constructions like those in (1) is to be grounded on Talmy's (1985, 1991) typological work on so-called 'conflation processes', which have been recently argued to involve the crucial role of morphosyntax when accounting for the relevant parametric variation (cf. Klipple (1997), Snyder (1995; 2001), and Mateu \& Rigau (1999; in press)).

\section{Small Clause Results and parametric variation}

As noted above, semanticocentric approaches to resultative-like constructions such as those in (1) can be granted descriptive validity but they do not provide any principled explanation of some important parameterizable morphosyntactic facts put forward by syntactically-oriented works like Snyder (1995), Klipple (1997), or Mateu and Rigau (1999; in press). To put it clearly, they cannot explain why resultative-like constructions like those in (1) exist in some languages (e.g., in English or German) but not in others (e.g., in Catalan or Spanish). They often limit themselves to stating this as a fact: e.g., the following statement in (51) can be taken as representative of adopting such a position. No explanation is pursued concerning why it is the case that in Romance languages "the two components" involved in a complex telic path of motion construction like She ran into the room, have to be obligatorily separated in the syntax. Why doesn't such a restriction hold in English?

(51) "Not all languages can conflate (118) <i.e., [BECOME (x, [LOC (y)]), BY [RUN (x)]]: JM> into a single verb name, of course. For those such as the Romance languages the two components have to be separated in the syntax. The core predication is the LCS for a general verb of directed motion such as enter. Thus the realization of (118) <cf. supra: JM> in Romance will look something like She entered the room running".

Spencer \& Zarestakya (1998: 33)

Before showing the non-trivial role of morphosyntax in (1), it will be useful to introduce some basic ideas from Talmy's $(1985,1991)$ typological work on so-called 'conflation processes'.

According to Talmy's descriptive typology, examples like those in (1) fall on the lexicalization pattern that is typically involved in satellite-framed languages like English or German. For example, consider the following complex telic path of motion construction in (52a). To put it in Talmy's (1985) terms, (52a) involves conflation of Motion with Manner, or

\footnotetext{
${ }^{19}$ The fact that the structurally-based paraphrase in (49) is not actually adequate for the so-called 'time-away construction' should not be of concern to syntacticians: Syntax has nothing to say concerning its (non-structurally based) idiomatic meaning: e.g., 'wasting time doing something'.
} 
alternatively, in Talmy's (1991) terms, (52a) involves conflation of AGENTIVEMOVE with SUPPORTING[EVENT]. By contrast, the corresponding counterpart of (52a) in a Romance language like Catalan typically involves a different lexicalization pattern (i.e., conflation of Motion with Path, the Manner component being expressed as an adjunct).
a. The boy danced into the room.
Conflation of Motion + Manner
b. Cat. El noi entrà a l'habitació ballant.
The boy went-into loc.prep the room dancing

In Germanic languages sentences like that in (52a) (or those in (1)) can be argued to be possible because of the following fact: the telic $P($ ath $)$ is not conflated into the verb (hence their satellite-framed nature), this verb being then allowed to be conflated with the so-called \{'Manner constituent'/ suPPORTING[EVENT] \}.

Quite interestingly, Hale \& Keyser's theory reviewed in section 3 allows us to express this fact in the following morphosyntactic terms: the absence of lexical saturation of the main verb (e.g., cf. $\mathrm{V}$ in (53a)) by the birelational element $\mathrm{P}$ allows this phonologically null unaccusative verb to incorporate a subordinate verb from an independent structure (e.g., the unergative one in (53b)), this incorporation/conflation process being carried out via a generalized transformation (cf. supra). The result of this syntactic operation is depicted in (54).

a.

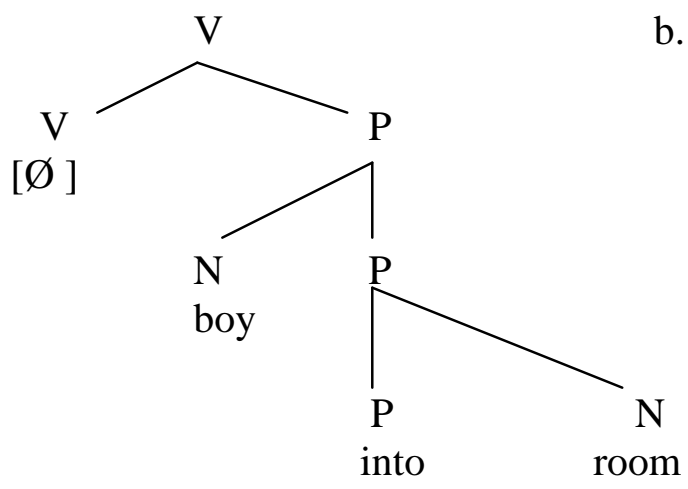

b.

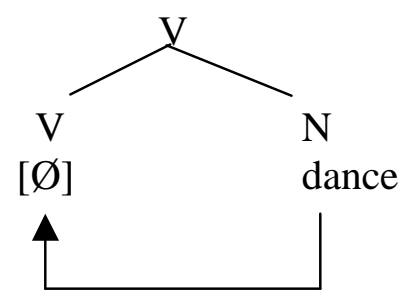

(54)

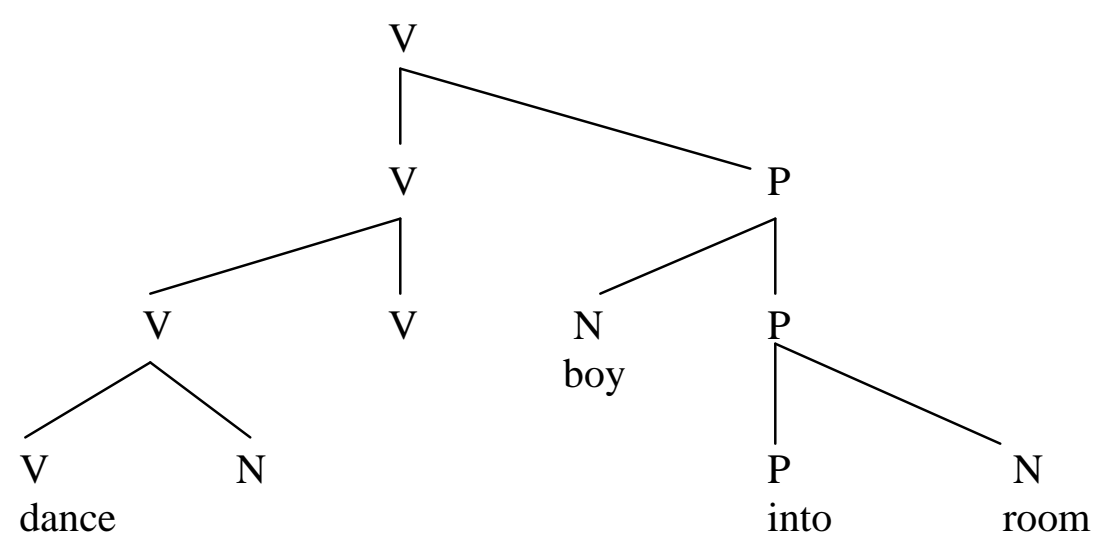

As above, the semantic intepretation to be associated to the complex syntactic argument structure in (54) can be depicted as in (55):

[[[DO-dance]-GO] [boy into room]] (i.e., 'the boy went into the room dancing'). 
By contrast, in Romance languages sentences like that in (52a) can be argued to be impossible because of the following fact: the $P($ ath $)$ is often conflated into the verb (hence their verb-framed nature), this verb being then prevented from being conflated with the socalled \{'Manner constituent'/ suPPORTING[EVENT] \}. To put it in the present morphosyntactic terms, the lexical saturation of $\mathrm{V}$ in (52a) by the relational directional element $\mathrm{P}$ prevents this unaccusative verb from incorporating a subordinate verb from an independent structure (e.g., the unergative one in (52b)).

For example, consider the following Catalan Path verbs in (56):

$$
\text { sortir 'to go out', entrar 'to go in', pujar 'to go up', baixar 'to go down'. (Catalan) }
$$

From a synchronic perspective, the conflation involved in the verbs in (56) can be regarded as a clear example of 'fossilized incorporation': roughly speaking, what corresponds to the motion verb and what to the telic Path relation cannot be distinguished any longer (cf. Mateu \& Rigau (in press) for more discussion).

By contrast, according to Talmy (1991), 'satellite' status must be attributed to Germanic preverbs like those involved in complex denominal verbs such as those in (57). As pointed out by Mateu (2001c), the syntactic analysis presented above for 'syntactic objects' like that in (52a) or those in (1)) can also be argued to hold for 'morphological objects' like those in (57). If such a move is correct, we are allowed to take this as evidence in favor of Hoekstra's $(1988,1992)$ or Marantz's (1997) criticisms of current Lexicalist approaches (see (58)).
a. $\quad$ Er ver-gärtner-te
sein gesamtes Vermögen. he VER(away)-gardener-ed his whole fortune 'In gardening, he used up all his fortune.'

b. Sie er-schreiner-te sich den Ehrenpreis der Handwerkskammer. she $E R$-carpenter-ed herself $\mathrm{DAT}_{\text {- }}$ the prize of the trade corporation 'She got the prize of the trade corporation by doing carpentry.'

Exs. from Stiebels (1998: 285-286)

(58) a. "(...) the common distinction between lexical word making and non-lexical sentence making is questionable at best".

$$
\text { Hoekstra (1988: 138) }
$$

b. ' “...) there is no reason not to build words in the syntax via 'merger' (simple binary combination) as long as there are no special principles of composition that separate the combining of words into phrases from the combining of morphemes into words".

$$
\text { Marantz (1997: } 205 \text { ) }
$$

For example, let us analyze the German example in (57a). The complex denominal verb ver-gärtner-te can be argued to involve two different syntactic argument structures, the main one being transitive (cf. (59a)), while the subordinate one being unergative (cf. (59b)). Crucially, the non-conflating (i.e., satellite) nature of the Path relation ver- in (59a) allows an independent lexical-syntactic verbal object (e.g., cf. the unergative argument structure in (59b)) to be conflated into the phonologically null main verb (i.e., the $\mathrm{V}$ in (59a)), the former 
providing the latter with phonological content (cf. (60)).$^{20}$ By contrast, Romance languages, which typically lack complex denominal verbs like those in (57), are verb-framed: the Path relation is conflated into the verb, this incorporation being fossilized (see (56)). This fossilized incorporation prevents a manner component (in our terms, an unergative argument structure) from being conflated into the main verb.

(59)

a.<smiles>C[IH][V]</smiles>

$[\varnothing]$<smiles>C[P-]C</smiles>

$\mathrm{N}$ b.

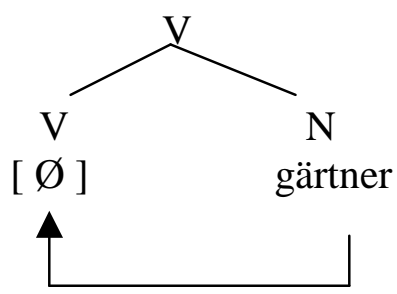

(60)

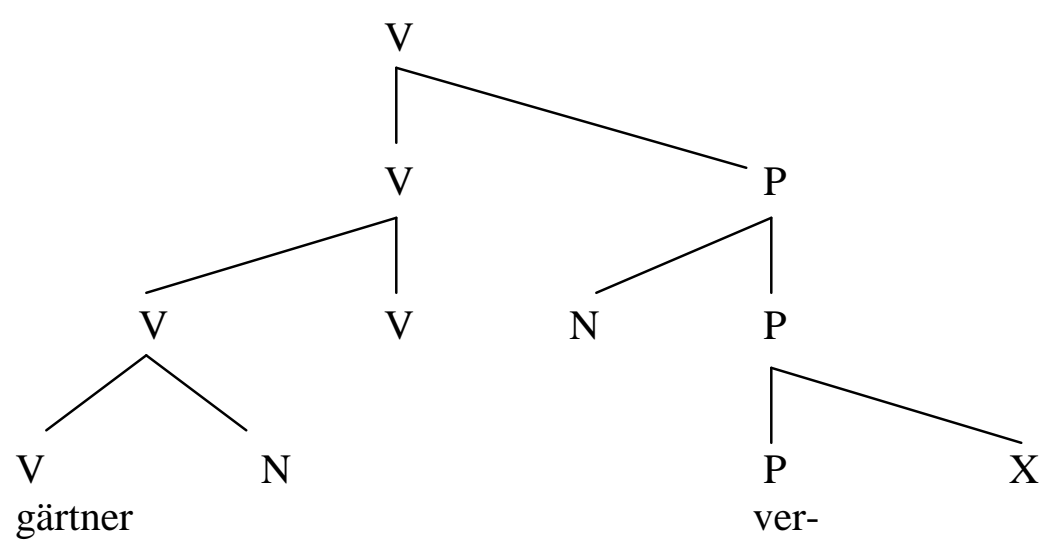

Furthermore, an additional step in the derivation of (60) appears to be involved: the affixal nature of the Path relation ver-forces it to be adjoined to the superior complex verbal head. By contrast, such an additional step is typically missing in English, as shown in (61a), even though some complex verbs similar to those in (57) can also be found in English: cf. the out-prefixation examples in (61b).

(61) a. He gambled all his fortune away.

b. I outplayed/outswam him.

Notice moreover that the lexicalization pattern accounting for the German examples in (57) is the same one holding for English complex denominal verbs like nail down or brick over. This seems then the adequate place to refute Stiebels's (1998: 298) words quoted in (62).

\footnotetext{
${ }^{20}$ Directional or resultative preverbs (prefixes/particles) and PPs involving a 'terminal coincidence relation' can be argued to be assigned the same argument structure (both contain a birelational element), the difference being that the former involve the conflation of a non-relational element $X$ (i.e., an abstract Ground) into a directional relational element $P$ (i.e., the 'Path'). $N$ in (59a) is to be interpreted as 'Figure/Theme'.
} 
(62) “(...) as with complex denominal verbs in German, Hale \& Keyser might have problems to account for complex denominal verbs in English (e.g., nail down, brick over the entrance, pencil out the entry, brush out the room) for which the role of the preverb should be clarified".

Stiebels (1998: 298)

As above, my rebuttal will be grounded on the descriptive basis of Talmy's (1985, 1991) typological work on conflation processes, which is not taken into account by Stiebels (1998). My lexical syntactic analysis of complex denominal verbs in English runs as follows. For example, consider the complex denominal verb to nail down, which can be regarded as the result of conflating two different syntactic argument structures, those in (63). (63a) is a transitive one, which contains a phonologically null verb subcategorizing for a PP as complement: Its head, the particle down, is to be taken as the result of conflating a nonrelational element $X$ (i.e., an abstract Ground) into the prepositional head expressing a terminal coincidence relation. ${ }^{21}$ Its specifier is to be interpreted as Figure/Theme. On the other hand, (63b) is a denominal verb, which is formed by conflating the nominal root nailinto another phonologically null verb expressing an activity (i.e., the activity of nailing).

a.

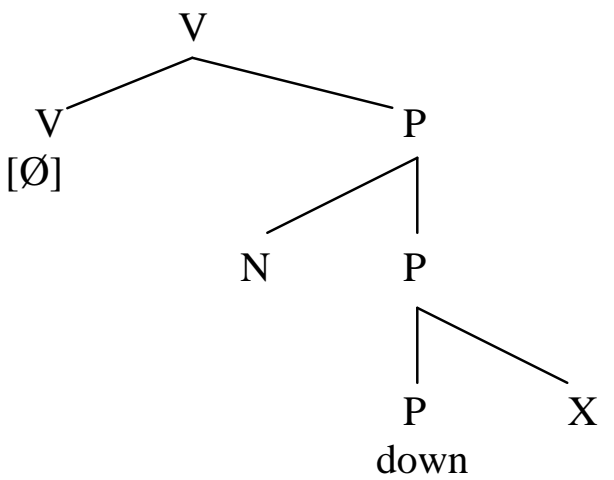

b.

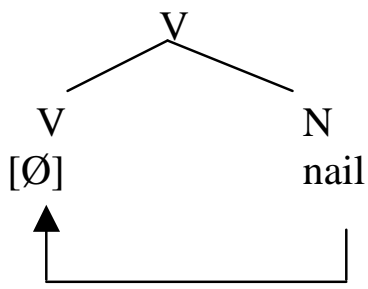

As stressed by Hale \& Keyser (1998), phonologically null properties associated to heads must be saturated at PF. As it stands, the syntactic argument structure in (63a) would then crash at PF. The Path relation (e.g., down) has non-conflating (i.e, satellite) status in English, this being unable to saturate the empty phonological properties of the verbal head in (63a). An option becomes then available: namely, to resort to an independent lexical syntactic object (e.g., that in (63b)) in order to saturate the empty phonological properties of the verb in (63a). The phonologically null properties of the verb in (63a) allow an independent lexical syntactic object with full phonological content (that expressed by nailing) to be conflated into it. The same generalized transformation operation we made use of above can also be argued to be resorted to when accounting for complex denominal verbs in English. The resulting complex lexical syntactic structure is depicted in (64):

\footnotetext{
${ }^{21}$ See Svenonius (1996) and Hale \& Keyser (2000) for more discussion on the argument structure of particles.
} 


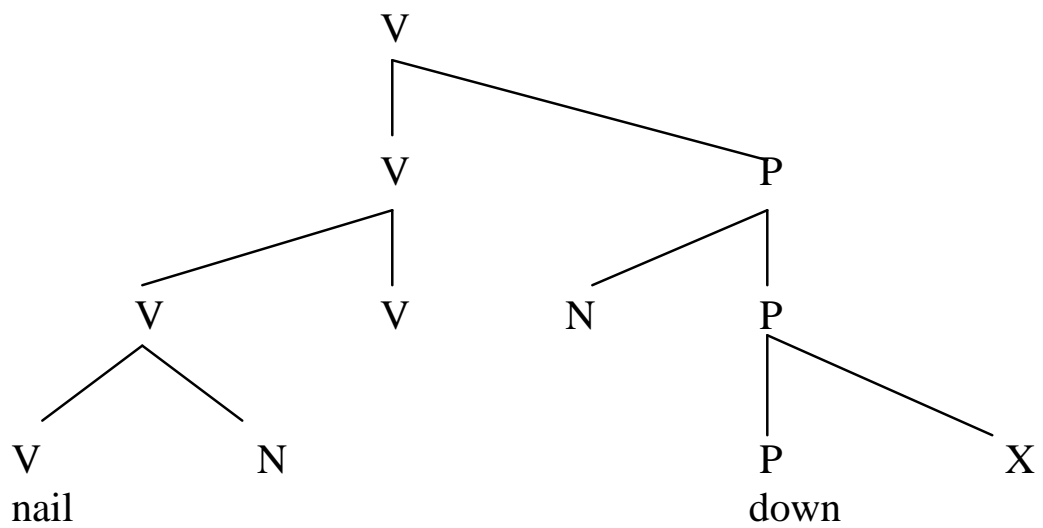

To conclude, a syntactic approach to resultative-like constructions like that pursued here is to be regarded as a particular way of attempting to provide a principled explanation of how to deal with the linguistic variation that is determined by morphosyntactic properties that do not affect functional categories, but lexical categories: ${ }^{22}$ Crucially, I have tried to show that there is a unified morphosyntactic explanation of why verb-framed languages like Romance do not have "syntactic objects" like those in (1) nor "morphological objects" like those in (57). Quite interestingly, notice that this can be taken as evidence for Hoekstra's or Marantz's claims quoted in (58).

Finally, some remarks concerning the crosslinguistic variation involved in (1) are in order:

\section{Concluding remarks}

(I) My approach can be regarded to be in tune with those syntactically-based aspectual approaches to resultative-like constructions like those in (1): e.g., Hoekstra (1988, 1992), Borer (1994), or Ritter \& Rosen (1998), among others. However, my work crucially parts ways with them in a non-trivial point: they neglect the so-called 'resultativity/directionality parameter' involved in the data in (1). Moreover, they omit the conflation process involved in their formation. As a result, they do not explain the crosslinguistic variation involved in Talmy's (1991) typological distinction. For example, let us take Borer's (1994) pioneering analysis into account: As it stands, it is not clear what prevents Romance languages from having John walked into the cave. Why is it the case that in Romance, John cannot be generated as the specifier of the functional category Aspevent-Measurer? In other words, why does the unaccusativization process involved in that sentence appear to be impossible in Romance? ${ }^{23}$ As shown above, my solution to such a puzzle has been argued to have nothing to do with aspectual properties associated to functional categories, but with morphosyntactic properties associated to lexical categories.

(II) On the other hand, let me emphasize that my intention was not to provide a complete picture of the crosslinguistic variation involved in resultative-like constructions like those in (1). I have concentrated myself on dealing with what I take to be some of the most relevant

\footnotetext{
22 See Snyder $(1995,2001)$ or Mateu \& Rigau (1999, in press) for more discussion on the claim that parametrized variation cannot be said to be limited to inflectional systems.

${ }^{23}$ Some exceptions can be found: e.g., in Italian unergative verbs like correre ('to run'), volare ('to fly') and a few others can enter into the unaccusative construction when a telic directional PP is present. My provisional proposal runs as follows: exceptional cases like It. correre must be lexically listed as both unergative and unaccusative, while It. camminare ('to walk') or Engl. to run and to walk are only lexically listed as unergative. The unaccusativization of manner of motion verbs and sound verbs in English is to be regarded as a regular process (see Levin \& Rappaport Hovav (1995), among others). But see the relevant discussion on (9) above.
} 
differences between satellite-framed languages like English and verb-framed languages like Romance. I leave it for another research agenda to work out the interrelations between the present Hale \& Keyserian syntactic approach and works adopting a wider crosslinguistic perspective (e.g., cf. Kim \& Maling (1997)).

\section{References}

Baker, M. (1997). "Thematic Roles and Syntactic Structure”. In: Haegeman, L. (ed.). Elements of Grammar. Dordrecht : Kluwer Academic Publishers

Borer, H. (1994). "The Projection of Arguments". In: Benedicto, E.; Runner, J. (eds.). Functional Projections. UMOP 17. Amherst, MA: University of Massachusetts.

Bouchard, D. (1995). The Semantics of Syntax. A Minimalist Approach to Grammar. Chicago \& London: The University of Chicago Press.

Chomsky, N. (1995). The Minimalist Program. Cambridge, MA: MIT Press.

Chomsky, N. (2001). "Beyond Explanatory Adequacy", ms. MIT, Cambridge, MA.

Goldberg, A. (1995). Constructions. A Construction Grammar Approach to Argument Structure. Chicago \& London: The University of Chicago Press.

Gruber, J. (1965). Studies on Lexical Relations. Doctoral dissertation. MIT, Cambridge, MA.

Hale, K. (1985). "Notes on world view and semantic categories: some Warlpiri examples". In: Muysken, P.; van Riemsdijk, H. (eds.) Features and projections. Dordrecht: Foris Publications.

Hale, K.; Keyser, S. J. (1993). "On Argument Structure and the Lexical Expression of Syntactic Relatons". In: Hale, K.; Keyser, S. J. (eds.). A View from Building 20: Essays in Linguistics in Honor of Sylvain Bromberger. Cambridge, MA: MIT Press.

Hale, K.; Keyser, S. J. (1997). "The Limits of Argument Structure”. In: Mendikoetxea, A.; Uribe-Etxebarria, M. (eds.). Theoretical Issues at the Morphology-Syntax Interface. Supplements of the International Journal of Basque Linguistics and Philology [XL]. Bizkaia: Servicio Editorial de la UPV.

Hale, K.; Keyser, S. J. (1998). “The Basic Elements of Argument Structure”. In: Harley, H. (ed.). MIT Working Papers in Linguistics 32. Papers from the UPenn/MIT Roundtable on Argument Structure. Cambridge, MA.

Hale, K.; Keyser, S. J. (1999a). “A Response to Fodor and Lepore, 'Impossible Words?”. Linguistic Inquiry 30.3: 453-466

Hale, K., ; S. J. Keyser (1999b). "Bound Features, Merge, and Transitivity Alternations". In: Pylkkänen, L. et al. (eds.) MIT Working Papers in Linguistics 35, Papers from the UPenn/MIT Roundtable on the Lexicon.

Hale, K.; Keyser, S.J. (2000). "On the Time of Merge”. MIT manuscript.

Harley, H. (1995). Subjects, Events and Licensing. Doctoral dissertation. MIT, Cambridge, MA.

Hoekstra, T. (1984). Transitivity. Foris: Dordrecht.

Hoekstra, T. (1988). "Small Clause Results”. Lingua 74: 101-139.

Hoekstra, T. (1992). “Aspect and Theta Theory”. In: Roca, I. M. (ed.). Thematic Structure: Its Role in Grammar. Dordrecht: Linguistic Models, Foris.

Hout, A. van (1996). Event Semantics of Verb Frame Alternation: A Case Study of Dutch and Its Acquisition. Doctoral dissertation, Tilburg: TILDIL dissertation series.

Jackendoff, R. (1983). Semantics and Cognition. Cambridge, MA: MIT Press.

Jackendoff, R. (1990). Semantic structures. Cambridge, MA: MIT Press.

Jackendoff, R. (1992). "Babe Ruth Homered His Way into the Hearts of America". In: Oehrle, R.; Stowell, T. (eds.). Syntax and the Lexicon. Syntax and Semantics, Volume 26. Academic Press Inc.

Jackendoff, R. (1997a). The Architecture of the Language Faculty. Cambridge, MA: MIT Press.

Jackendoff, R. (1997b). “Twistin' the night away”. Language 73: 534-559.

Kim, S.; Maling, J. (1997). "A Crosslinguistic Perspective on Resultative Formation”. Texas Linguistic Forum 38: 189-204.

Kiparsky, P. (1997). "Remarks on Denominal Verbs". In: Alsina, A. et al. (eds.). Complex Predicates. Stanford, Clf.: CSLI.

Klipple, E. (1997). "Prepositions and Variation". In: Di Sciullo, A-M. (ed.). Projections and Interface Conditions. New York/Oxford: Oxford University Press.

Kratzer, A. (1995). "Stage-Level and Individual-Level Predicates". In: Carlson, C.; Pelletier, F. (eds.). The Generic Book. Chicago: The University of Chicago Press. [Ms. 1988].

Kratzer, A. (1996). "Severing the External Argument from the Verb”. In: Rooryck, J.; Zaring, L. (eds.). Phrase Structure and the Lexicon. Dordrecht: Kluwer.

Legendre, G. (1997). "Secondary Predication and Functional Projections in French". Natural Language and Linguistic Theory 15: 43-87.

Levin, B.; Rapoport, T. (1988). “Lexical Subordination”. CLS 24: 275-289. 
Levin, B.; Rappaport Hovav, M. (1995). Unaccusativity. At the Syntax-Lexical Semantics Interface. Cambridge, MA: MIT Press.

Marantz, A. (1992). "The Way-Construction and the Semantics of Direct Arguments in English: A Reply to Jackendoff". In: Oehrle, R.; Stowell, T. (eds.). Syntax and the Lexicon. Syntax and Semantics, 26. Academic Press Inc.

Marantz, A. (1997). "No Escape from Syntax: Don't Try Morphological Analysis in the Privacy of Your Own Lexicon". U.Penn Working Papers in Linguistics 4.2: 201-225.

Mateu, J. (1999) "Universals of semantic construal for lexical-syntactic relations". Paper presented at the 1999 GLOW Workshop: Sources of Universals. University of Potsdam, Potsdam. GLOW Newsletter 42: 77. Distributed as GGT-99-4 Research Report, Universitat Autònoma de Barcelona, Bellaterra.

Mateu, J. (2000a). "Paths and telicity in idiomatic constructions: a lexical-syntactic approach to the way construction". Paper presented at the 2000 ESSLLI Workshop on Paths and Telicity in Event Structure, University of Birmingham [submitted].

Mateu, J. (2000b). "Why Can't We Wipe the Slate Clean? A Lexical-Syntactic Approach to Resultative Constructions". Catalan Working Papers in Linguistics 8: 71-95.

Mateu, J. (2001a). "Unselected Objects”. In: Dehé, N.; Wanner, A. (eds.). Structural Aspects of Semantically Complex Verbs. Frankfurt/Berlin: Peter Lang Verlag.

Mateu, J. (2001b). "Locative and locatum verbs revisited. Evidence from Romance”. In: D’Hulst, Y.; Rooryck, J.; Schroten, J. (eds.). Romance languages and linguistic theory 1999. Amsterdam/Philadelphia: John Benjamins.

Mateu, J. (2001c). "Complex denominal verbs and parametric variation". Paper presented at the $3^{r d}$ Mediterranean Meeting on Morphology. Universitat Pompeu Fabra, Barcelona. To appear in: Booij, G. et. al. (eds.). Proceedings of the $3^{\text {rd }} M M M$. Barcelona: IULA Publications.

Mateu, J.; L. Amadas (2001). "Syntactic tools for semantic construal". Paper presented at the $1^{\text {st }}$ Conference on Tools in Linguistic Theory (TiLT). Utrecht Institute of Linguistics OTS, Utrecht.

Mateu, J.; Rigau, G. (1999). "Universals of Lexical-Syntactic Typology and Parametric Variation". Paper presented at the 1999 GLOW: Universals. ZAS, Berlin. GLOW Newsletter 42, 38-39.

Mateu, J.; Rigau, G. (in press). "A Minimalist Account of Conflation Processes: Parametric Variation at the Lexicon-Syntax Interface." In: Alexiadou, A. (ed.). Theoretical Approaches to Universals. LA Series. Amsterdam/Philadelphia: John Benjamins.

Pustejovsky, J. (1991). “The Syntax of Event Structure”. Cognition 41: 47-82.

Ritter, E.; Rosen, S.T. (1998). "Delimiting Events in Syntax". In: Butt, M.; Geuder, G. (eds.) The Projection of Arguments. Lexical and Compositional Factors. Stanford, CA: CSLI Publications.

Snyder, W. (1995). Language Acquisition and Language Variation: The Role of Morphology. Doctoral dissertation. MIT, Cambridge: MA.

Snyder, W. (2001). "On the nature of syntactic variation: Evidence from complex predicates and complex wordformation”. Language 77.2: 324-342.

Spencer, A.; Zaretskaya, M. (1998). "Verb prefixation in Russian as lexical subordination". Linguistics 36: 1-39.

Stiebels, B. (1998). "Complex denominal verbs in German and the morphology-semantics interface". In: Booij, G.; van Marle, J. (eds.). Yearbook of Morphology 1997: Kluwer.

Stowell, T. (1981). Origins of Phrase Structure. Doctoral dissertation. MIT, Cambridge, MA.

Svenonius, P. (1996). "The verb-particle alternation in the Scandinavian languages". University of Troms $\emptyset$ manuscript.

Talmy, L. (1985). "Lexicalization Patterns: Semantic Structures in Lexical Forms”. In: Shoepen, T. (ed.). Language Typology and Syntactic Description III: Grammatical Categories and the Lexicon. Cambridge: CUP.

Talmy, L. (1991). "Path to realization: A typology of event conflation". Proceedings of the Berkeley Linguistics Society 17: 480-519.

Tenny, C. (1994). Aspectual Roles and the Syntax-Semantics Interface. Dordrecht: Kluwer.

Uriagereka, J. (1998). Rhyme and Reason. An Introduction to Minimalist Syntax. Cambridge, MA: MIT Press.

Jaume Mateu Fontanals

Grup de Gramàtica Teòrica

Departament de Filologia Catalana

Facultat de Filosofia i Lletres

Universitat Autònoma de Barcelona

08193-Bellaterra (Barcelona)

Spain

jaume.mateu@uab.es 